\title{
Flexible Hot Rolling of Extruded Shapes of Aluminum Alloy EN AW-6082
}

\author{
Grydin, O. ${ }^{1, a^{*}}$, Sotirov, N. ${ }^{2, b}$, Samsonenko, A. ${ }^{3, c}$, Biba, N. ${ }^{4, d}$, Andreiev, A. ${ }^{1, e}$, \\ Stolbchenko, M. ${ }^{1, f}$, Behr, T.-M. ${ }^{1, g}$, Frolov, la. ${ }^{3, h}$, Schaper, M. ${ }^{1, i}$ \\ ${ }^{1}$ Department of Material Science, Paderborn University, Paderborn, Germany \\ ${ }^{2}$ BENTELER Automotive, Paderborn, Germany
}

${ }^{3}$ Department of Metal Forming, National Metallurgical Academy of Ukraine, Dnipro, Ukraine

${ }^{4}$ MICAS Simulations Ltd., Oxford, United Kingdom

agrydin@lwk.uni-paderborn.de, bnikolay.sotirov@benteler.com,

'samsonenko@metal-forming.org, ${ }^{\mathrm{d}}$ nick@qform3d.com, eandreiev@lwk.upb.de,

'stolbchenko@lwk.uni-paderborn.de, 9teresabehr@gmail.com, hfrolov@metal-forming.org,

ischaper@lwk.uni-paderborn.de

Keywords: Hot Deformation, Rolling, Extruded Shape, Aluminum

\begin{abstract}
One of the strategies employed to lower weight and to decrease material consumption is reducing part thickness itself. Thus, functionally graded materials in which structural reinforcement is adjusted locally, are of great interest. With regard to conventional industrial processes, such as extrusion or flexible cold rolling, thickness variations can only be achieved either longitudinally or through the cross-section of the semi-finished products. Hence, a combined thickness variation (along both axes) is difficult to generate solely by extrusion or rolling. A simultaneous thickness variation in both directions, however, would enable further weight savings in structural components such as car body parts.

In this study, a promising approach with extruded shapes, serving as a billet for a flexible hot rolling process, is elaborated upon. By employing the described process modification, shapes with simultaneous thickness variations in longitudinal as well as in transverse direction are feasible. Initial numerical analysis reveals the weight-saving potential of using these semi-finished products for structural parts in a car body. A demonstration of the production process for the semi-finished parts and the occurring challenges are discussed. To verify and adjust the new technology, a numerical model of the flexible hot rolling process has been created based on the finite element software QForm VX. This model is also employed for tool design optimization to produce semifinished components with the required geometrical quality. Finally, the results of hot rolling experiments conducted using the adjusted roll design are presented.
\end{abstract}

\section{Introduction}

As automakers have sought to lower weights and reduce the use of materials in modern car components, aluminum and its alloys, which simultaneously exhibit relatively low density and a wide variety of properties, are being increasingly applied due to their lightweight potential. Another strategy employed in addition to lightweight material is reducing the volume of a part by varying the part's thickness to provide additional structural reinforcement only where it is necessary.

One of the well-studied and established industrial processes to produce thickness variation in a single sheet or shapes is extrusion, during which variation of thickness can primarily be achieved in transverse direction [1]. Another production process, which allows thickness variation in either the longitudinal or transversal direction, is flexible rolling [2] or strip profile rolling [3].

Although both processes are already well-studied and industrially approved, they do not allow sheets to be produced with simultaneous thickness variation in both transverse and longitudinal directions. 
Thus, the combination of extrusion and flexible rolling could expand the limits of both technologies and enable production of structural parts with both higher weight savings and without affecting their performance, e.g. in a crash.

FEM simulation of a 3-point bending test confirms that additional thickness reductions in a B-pillar in longitudinal direction in the marked areas in the figure below do not affect crash performance in comparison with a B-pillar produced from a shape with thickness variation only in the transverse direction (Fig. 1). These additional longitudinal thickness changes provide a weight savings of $0.56 \mathrm{~kg}$ per component. Thus, both material consumption and production costs can be reduced when using high-value aluminum alloys.

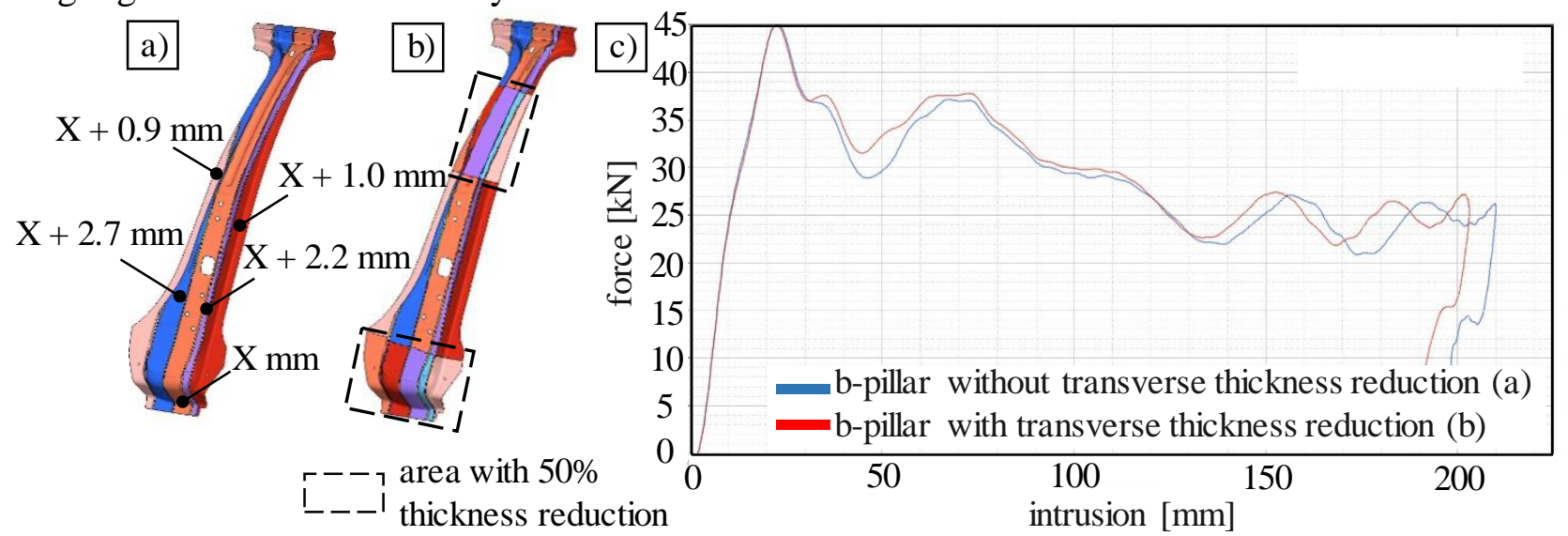

Fig. 1: B-pillar with variable thicknesses in transverse direction (a); modified light-weight B-pillar with variable thicknesses in both transverse and longitudinal directions (b); calculated forceintrusion-curves in bending test (c)

In order to ensure the potential weight saving, the rolling process of the extruded shape was investigated. The hot rolling process of extruded shapes with constant thickness reduction was experimentally and numerically investigated as a first step towards the practical implementation of flexible rolling of shapes allowing the production of semi-finished product for B-pillars with thickness variation in two directions. The purpose of the present study is the experimental and numerical investigation of the hot rolling process with constant thickness reduction of extruded shapes. This research is a first step towards the practical implementation of flexible rolling of extruded shapes, which will enable production of semi-finished product for B-pillars with a twodirectional thickness variation.

\section{Modelling and Validation}

\section{Simulation}

A numerical model for the thermo-mechanical simulation of a hot rolling process with constant thickness reduction was developed using the software QForm VX [4].

The investigated extruded shape exhibits a thickness variation only along the bottom wall, which is $170 \mathrm{~mm}$ wide (see Fig. 2a). The total width of the shape, including two equal side walls each with a constant thickness of $« X+2.7 » \mathrm{~mm}$, amounts to approx. $450 \mathrm{~mm}$. As the construction of available rolling mill can only accommodate rolls with a maximum length of $300 \mathrm{~mm}$, only the bottom wall of the extruded shape was used as a billet for experiments and numerical simulation.

Extruded forms used for the production of B-pillars (see Fig. 1a) and a schematic view of the graphical model used for simulation trials are presented in Fig. 2.

In the simulation, the rolls were modelled as a rigid body, i.e. no elastic or plastic strain of the rolls was calculated during simulation. The stress-strain data for the investigated alloy EN AW-6082 was measured during compression tests in a deformation dilatometer "Bähr DIL805A/D". The flow curves were analyzed in a temperature range from $350{ }^{\circ} \mathrm{C}$ to $550{ }^{\circ} \mathrm{C}$ and at strain rates of $0.1 \mathrm{~s}^{-1}$, $1.0 \mathrm{~s}^{-1}, 10.0 \mathrm{~s}^{-1}$. The contact friction and heat dissipation were minimized using graphite slices 
between sample and compression punches. The obtained data without any additional processing has been implemented as tables in the simulation software to predict material flow during hot deformation in accordance with model described in [5]. The mesh for the shape used tetrahedrons with a size of $3 \mathrm{~mm}$, while the mesh elements of the profile in the rolling gap were resized down to $1 \mathrm{~mm}$. The mesh for the rolls also used tetrahedrons with a constant size of $10 \mathrm{~mm}$. The friction from plastic strain during rolling has been characterized using Levanov's friction model [6]. The temperatures of both sample and rolls were set to $540{ }^{\circ} \mathrm{C}$ and $20^{\circ} \mathrm{C}$ respectively. The heat transfer coefficient between the shape and rolls was calculated using temperature measurements performed during experiments and set to $40000 \mathrm{~W} / \mathrm{m}^{2} \cdot \mathrm{K}$. The obtained value is in an agreement with values presented in [7]. The displacement of the material in $\mathrm{X}$ and $\mathrm{Z}$ direction before the rolling gap was constrained. The calculation of fracture was performed using Latham \& Cockcroft criterion [8].
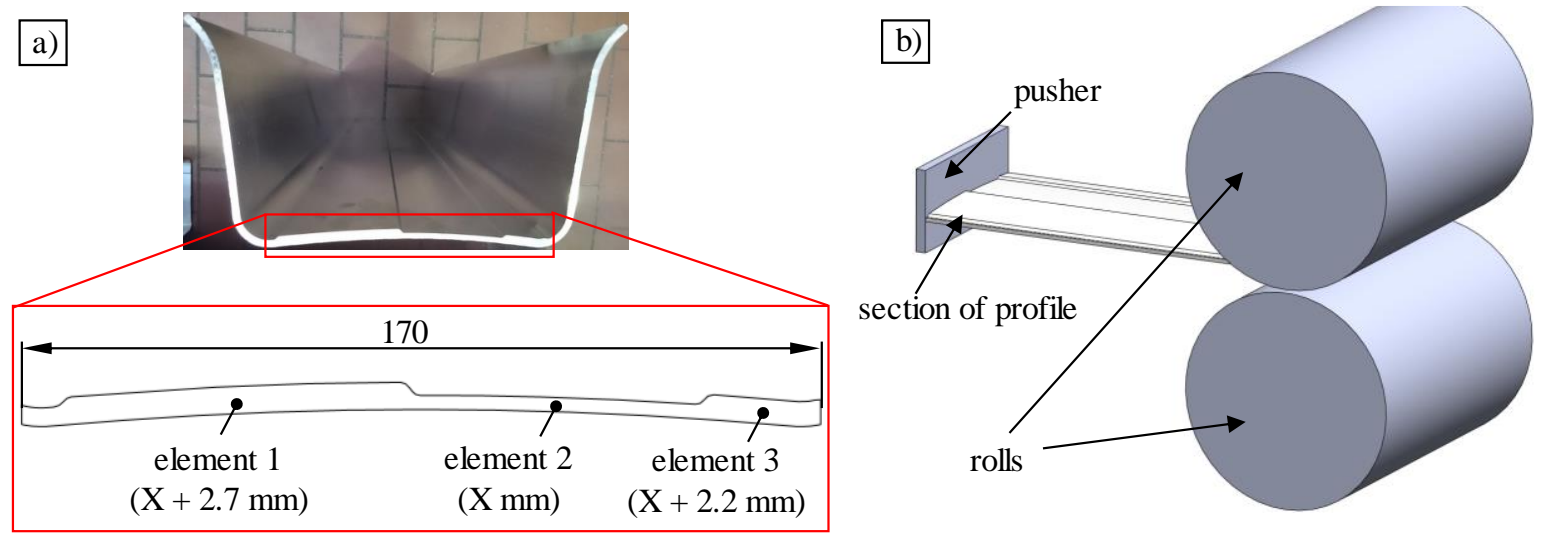

Fig. 2: Extruded shape and cross-section of samples cut from this shape for investigation (a); graphical model of rolls with profiled samples used for simulation trials (b). The thickness of elements of the extruded shape prior to processing is given in parentheses

Using the described numerical model, a series of three simulations was performed:

1) Rolling with plastic reductions of $30 \%$ and $50 \%$ in relation to the initial thickness of element 1 (see Fig. 2a) using two flat rolls with a diameter of $210 \mathrm{~mm}$ rotated at the angular speed of $14 \mathrm{rad} \mathrm{s}^{-1}$.

2) Rolling with reduction of $50 \%$ in relation to the initial thickness of element 1 (see Fig. 2a) using one flat roll with a diameter of $210 \mathrm{~mm}$ and one profiled roll. The angular speed of both rolls amounted to $14 \mathrm{rad} \mathrm{s}^{-1}$.

3) Flexible rolling with local reduction of $50 \%$ along the length of the material using one flat roll with a diameter of $210 \mathrm{~mm}$ and one profiled roll, which allows a semi-finished product for b-pillar to be obtained with thickness variations as shown in Fig. 1b. The angular speed of both rolls amounted to $14 \mathrm{rad} \mathrm{s}^{-1}$. As in previous cases, rolling reduction is related to the initial thickness of element 1 (see Fig. 2a).

\section{Experiments}

To validate the simulation model, hot rolling trials were performed using extruded shapes with the thickness variation in transverse direction as in Fig. 2a. The shapes of the EN AW-6082 alloy were provided by BENTELER Automotive GmbH. Before hot rolling, the samples were heated up to $560{ }^{\circ} \mathrm{C}$ in an electric furnace, with subsequent holding for $30 \mathrm{~s}$ at this temperature. To control the temperature during heating, rolling and quenching, a thermocouple was positioned in a hole drilled into the front face of each sample. After heating, samples were transferred from the furnace to the rolling stand between two pre-heated ceramic plates to reduce heat loss due to contact with air, and thus to achieve a more homogeneous temperature distribution in the strip before rolling. The samples were inserted into the rolling gap as the temperature decreased from $560{ }^{\circ} \mathrm{C}$ to $540{ }^{\circ} \mathrm{C}$. Two series of hot rolling experiments were performed in accordance with the performed simulation trials: 
1) Rolling with reductions of $30 \%$ and $50 \%$ in relation to the initial thickness of element 1 (see Fig. 2a) using two flat rolls with a diameter of $210 \mathrm{~mm}$ rotated at the angular speed of $14 \mathrm{rad} \mathrm{s}^{-1}$.

2) Rolling with reduction of $50 \%$ in relation to the initial thickness of element 1 (see Fig. 2a) using one flat roll with a diameter of $210 \mathrm{~mm}$ and one profiled roll. The angular speed of both rolls amounted to $14 \mathrm{rad} \mathrm{s}^{-1}$.

After exiting the roll gap, the samples were immediately quenched in a water-bath.

The experiments for flexible hot rolling with local reduction of $50 \%$ along the length of shape have not been yet performed to date and are the aim of future work.

\section{Characterization of Mechanical Properties and Microstructure}

One of the rolled samples from the second experimental series was naturally aged for 16 hours after water quenching and subsequently artificially aged at a temperature of $150{ }^{\circ} \mathrm{C}$ for 24 hours [9]. To characterize the mechanical properties of each element of rolled, quenched, and age-hardened material, the Brinell hardness measurements as well as tensile tests were performed. During the Brinell hardness measurements, each thickness element of the sample was tested three times to obtain an average hardness value, with the testing force set at $62.5 \mathrm{kgf}$ for an indentation sphere with a diameter of $2.5 \mathrm{~mm}$. Additionally, three specimens with gage length of $30 \mathrm{~mm}$ and width of $8 \mathrm{~mm}$ were cut from each element of the sample by means of wire erosion, and subsequently tested with a cross-head speed of $4 \mathrm{~mm} / \mathrm{min}$ to measure $0.2 \%$ yield strength (YS), ultimate tensile strength (UTS), and elongation at fracture $\left(\mathrm{E}_{\mathrm{lt}}\right)$.

For characterization of the grain microstructure, the samples were cold mounted, mechanically ground and polished, and finally vibration-polished. Afterwards, samples were anodised in Barker's solution, $5 \mathrm{ml} \mathrm{HBF} 4(48 \%)$ in $200 \mathrm{ml}$ water, and then examined with an optical microscope under polarized light. Grain size of the investigated micrographs was measured according to the standard DIN EN ISO 643 using the intercept method, whereby the interception line was drawn transversely to the previous extrusion/rolling direction (RD), i.e. alongside the normal direction. At least 100 intercepts were taken into account to calculate grain size.

\section{Results}

Comparison of Experimental and Simulation Results

A comparison of simulated shapes and the true shapes after hot rolling using two flat rolls with reductions of $30 \%$ and $50 \%$ is presented in Fig. 3.

Independent of their rolling reduction, the hot-rolled samples exhibit significant waviness of the edges. This effect can be explained by the inhomogeneity of local rolling reductions in different thickness elements: the nominal rolling reduction of $30 \%$ or $50 \%$ takes place only in the area of element 1 . Simultaneously, due to the constant diameter of the rolls, the elements 2 and 3 undergo lower rolling reduction because of their lower initial thickness. Thus, these elements elongate less during rolling than element 1 . Furthermore, in the case of nominal rolling reduction of $30 \%$, the reduction of element 2 amounts to $0 \%$ because its initial thickness is less than the rolling gap of $\ll \mathrm{X}+1.2 » \mathrm{~mm}$; in the case of a rolling reduction of $50 \%$, it amounts to approximately $7 \%$. This means that the material in the area of element 2 is not being elongated due to compression as a result of rolling reduction, but is rather being plastically stretched by neighboring elements 1 and 3 due to the higher compression and simultaneous elongation of these elements. Such inhomogeneity of deformation during rolling leads not only to the waviness of shapes, but also to local necking for a rolling reduction of $30 \%$ (Fig. 3c) or even to the formation of zipper cracks during a rolling reduction of $50 \%$ in the element 2 (Fig. 3d).

The developed numerical model predicted the same results as were shown in the experiment: the waviness of shapes, as well as necking or cracking in element 2 depending on the rolling reduction (see Fig. 3a and 3b, 3d and 3e). Table 1 gives an overview of the maximum rolling forces measured in the hot rolling experiments and those predicted during simulation. 


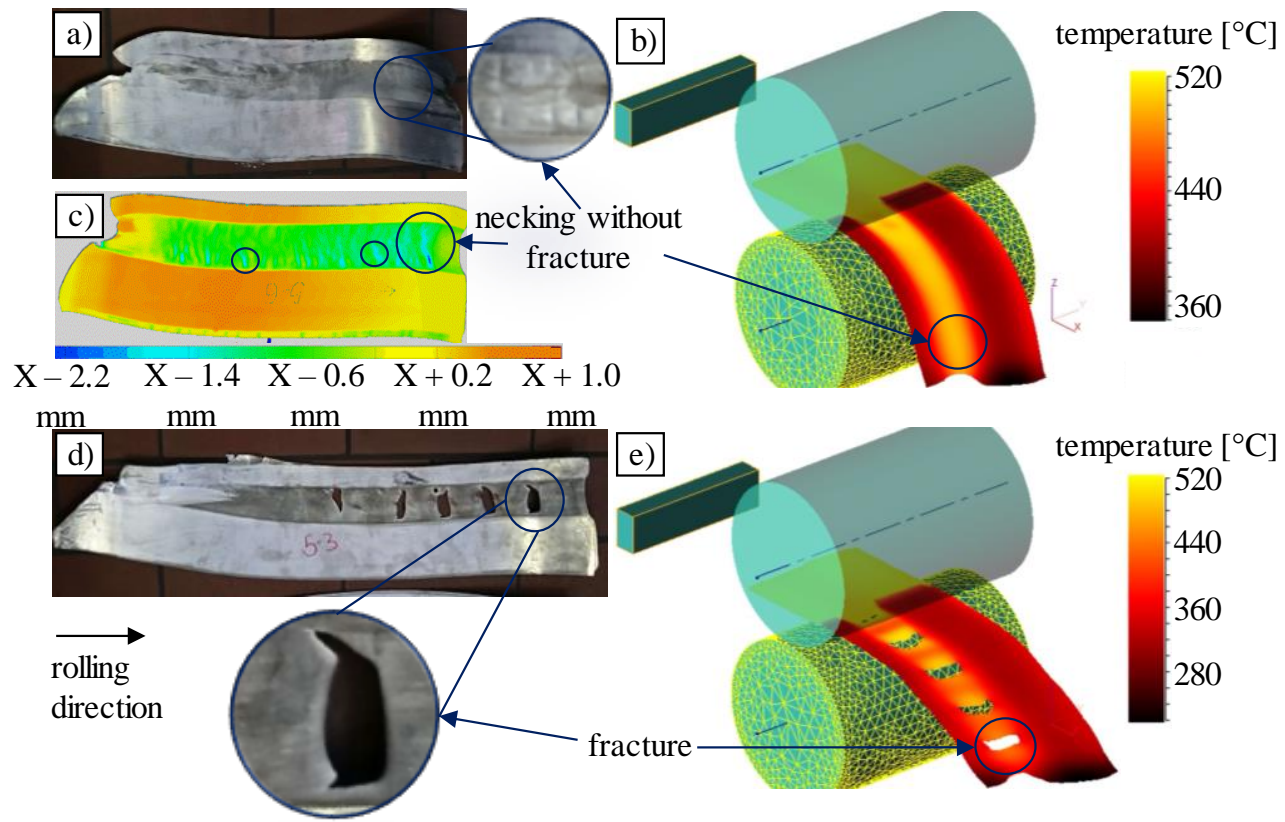

Fig. 3: Shapes after hot rolling with two flat rolls and (a) reductions of $30 \%$ and (d) $50 \%$; results of simulation of corresponding experiments ( $b$ and e) and distribution of thickness in shape after hot rolling with reduction of $30 \%$ determined with GOM Atos (c)

Table 1: Maximal Rolling Force from Experiment and Simulation for Flat Rolls

\begin{tabular}{|l|l|l|}
\hline \multirow{2}{*}{ Rolling Reduction } & Maximum Rolling Force $[\mathrm{kN}]$ \\
\cline { 2 - 3 } & Experiment & Simulation \\
\hline $30 \%$ & 176 & 180 \\
\hline $50 \%$ & 620 & 328 \\
\hline
\end{tabular}

The maximum rolling force from the experiment with a rolling reduction of $30 \%$ is in agreement with the value obtained from the simulation. However, the maximal rolling force from the experiment with rolling reduction of $50 \%$ is roughly twice as high as that from simulation. This fact can be explained by an increasing instability of rolling process with increasing rolling reduction. The features of the instability are:

1) overlapping of both sides of the sample before entering the rolling gap, which takes place at rolling with rolling reduction of $50 \%$ and does not occur for a rolling reduction of $30 \%$.In the simulation model, this effect has not been considered due to restriction of movement of the shape in $\mathrm{X}$ and $\mathrm{Z}$ directions;

2) crack formation during the experiment with rolling reduction of $50 \%$. The effect influences the resulting rolling force, and this influence has not been implemented correctly in the simulation model.

In Fig. 4, the temperature curves of elements 1 and 2 from the experiment with a rolling reduction of $50 \%$ are compared with the corresponding predicted temperature shapes from the simulation. The temperature curves predicted during the simulation are generally in agreement with those from the experiment, regardless of the element thickness of the rolled sample.

To summarize, the comparison of experimental and simulation results showed that the developed numerical model is appropriate for a reliable prediction of the hot rolling process of aluminum materials. Therefore, a modified shape of one of the work rolls was developed using the simulation model. The modified roll contour should enable a hot rolling process of the extruded sample without the defects mentioned above. The main task was to adjust the roll radius along the length of one of the work rolls to achieve locally the same rolling reduction in each element of the sample during hot rolling , and thus to avoid the initiation of necking and cracks. 


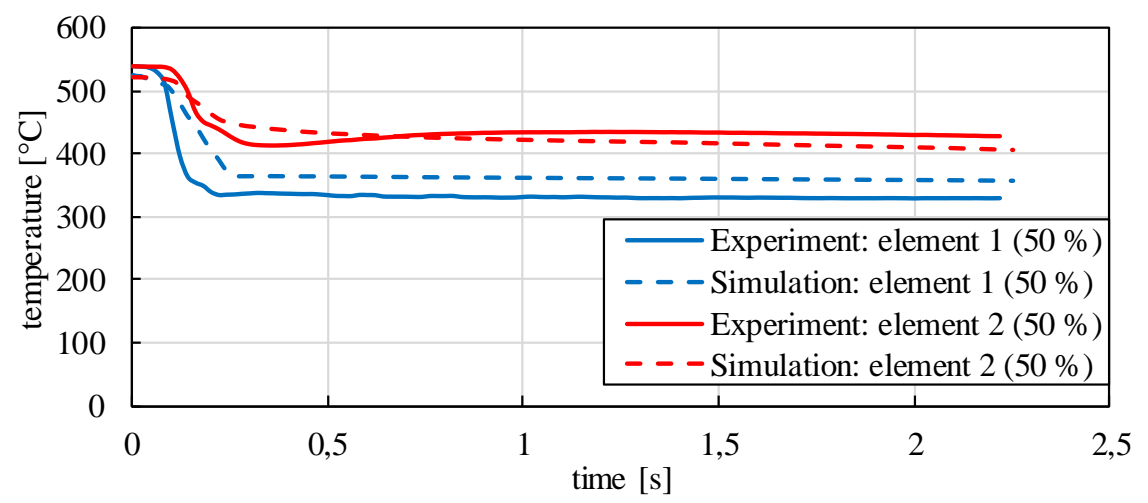

Fig. 4: Experimentally Obtained and Simulated Temperature Profiles of Elements 1 and 2 during Rolling using the Non-Profiled Cylindrical Rolls

Due to the fact that the rolling reduction of $50 \%$ is critical in terms of crack initiation in element 2 , the shape of one of the rolls was designed to allow hot rolling with a reduction of $50 \%$ without defects. Thus, the section of one of the working rolls which is in contact with element 1 retained the initial roll diameter of $210 \mathrm{~mm}$. The roll diameters of those sections which would deform elements 2 and 3 were correspondingly increased to ensure the rolling reduction of $50 \%$ simultaneously in all 3 elements of the rolled sample. The diameter and shape of the second roll was left unchanged, i.e. a flat roll $210 \mathrm{~mm}$ in diameter. The results of the simulation as well as the profile after hot rolling using one straight cylindrical roll and one profiled roll with the modified shape are presented in Fig. 5.
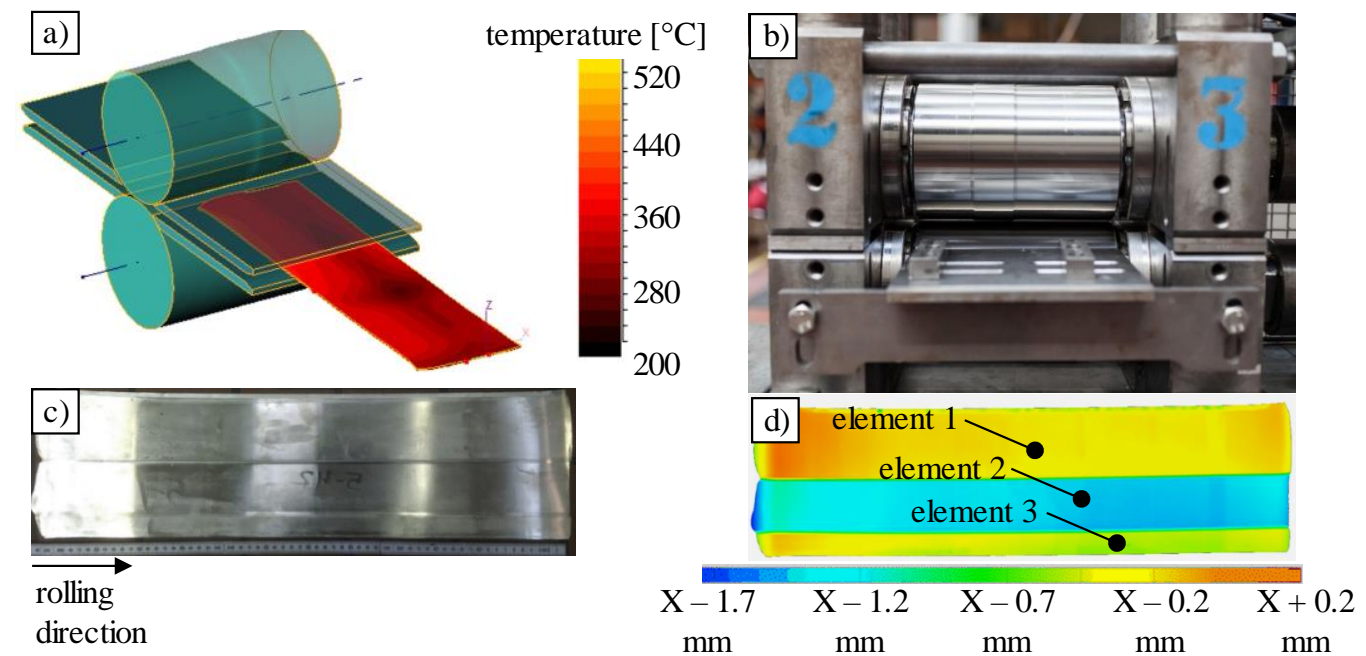

Fig. 5: Simulation and experimental results of the hot rolling process using the roll with modified shape: a) view of the simulated rolling process; b) the roll with modified shape installed in rolling mill; c) the extruded material, hot-rolled with a reduction of $50 \%$ using modified roll; d) thickness distribution in the hot-rolled material, determined with GOM Atos

The flat rolling process using the designed profiled roll allows straight and defect-free shapes with reduced cross section to be produced. Therefore, the next step consists in the practical implementation of a flexible rolling process of the investigated extruded shapes, which seems to be feasible based on simulation results (Fig. 6a). Figure 6b shows that a flexible rolling process can obtain the desired thickness distribution in semi-finished products, which is required for the production of the modified light-weight B-pillar from Fig. $1 \mathrm{~b}$.

According to simulation results, the flexible rolling of straight and defect-free shapes with desired thickness variation in both longitudinal and transverse direction can be realized on available rolling stand using one flat roll and one developed profiled roll. 
The simulation of 3-point bending tests were performed using designed B-pillar geometry, i.e. no calculations were conducted to simulate corresponding deep drawing operation for B-pillar shaping from flexibly rolled profiles. This is the aim of on-going work.

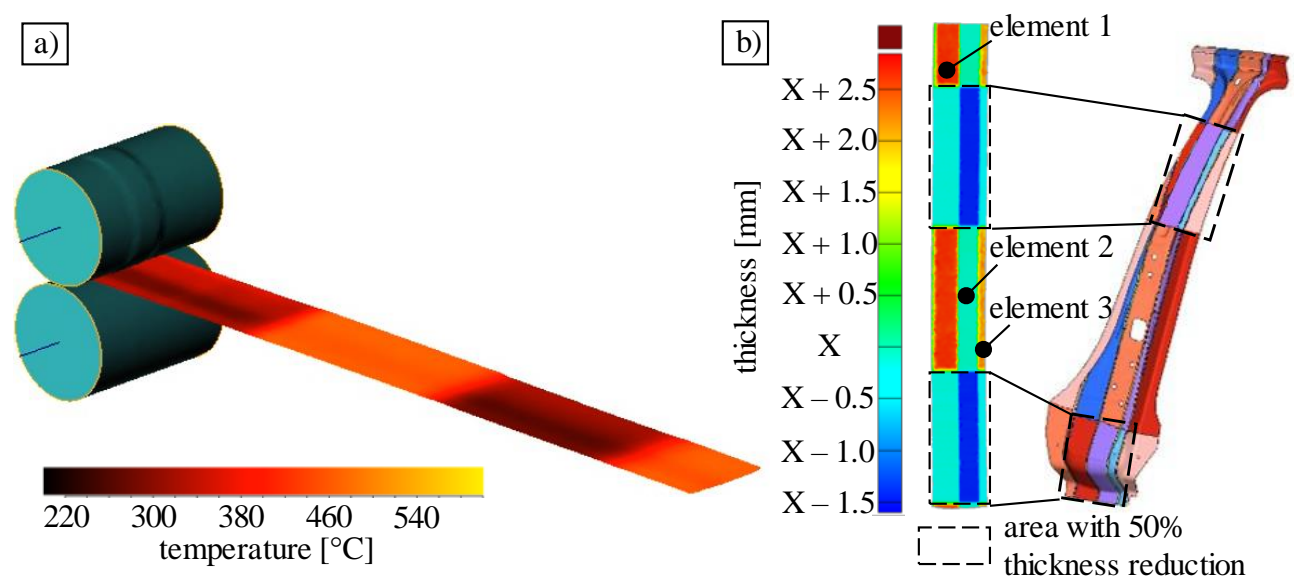

Fig. 6: Results of the simulation of the flexible rolling process: a) view of simulated flexible rolling process; b) thickness distribution in flexibly rolled material from simulation, measured with GOM Inspect and modified B-pillar

\section{Microstructure and Mechanical Properties}

After hot rolling and water quenching, the defect-free hot-rolled shapes were both naturally and subsequently artificially aged to bring the material into the T6 condition. The microstructure of the hot-rolled material is presented in Fig. 7.
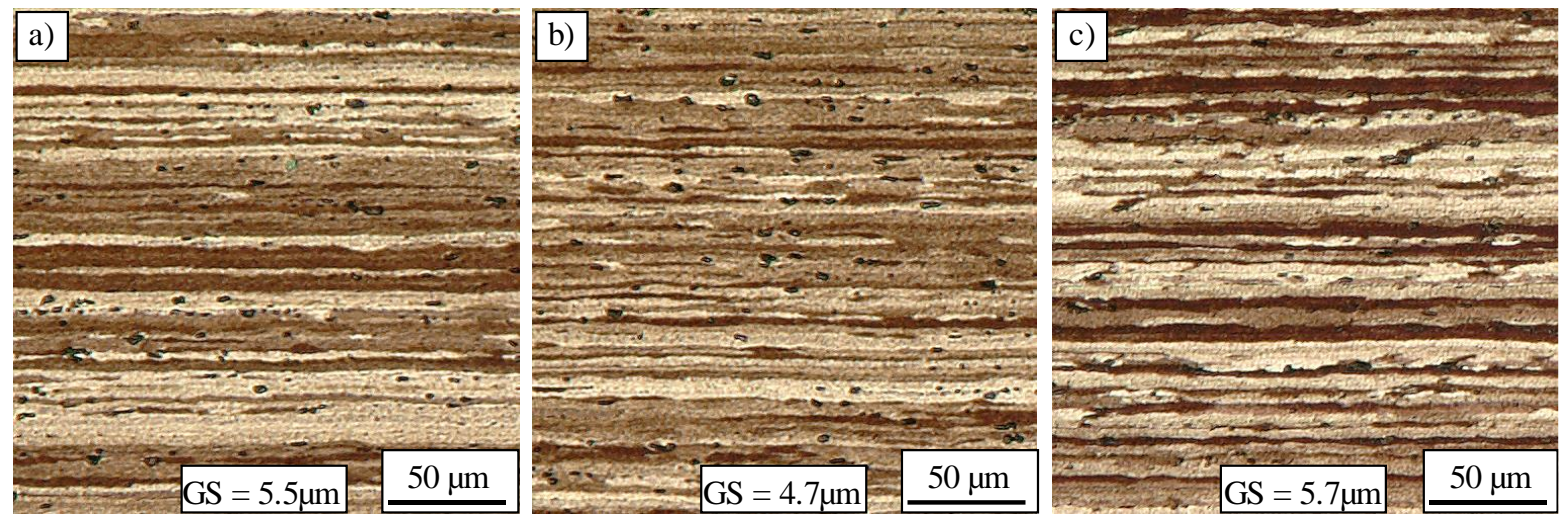

Fig. 7: Microstructure of hot-rolled shape: a) element 1; b) element 2; c) element 3. GS - grain size

Independent of the element, the microstructure consists of long, stretched grains and is typical for extruded material. Thus, the solution annealing of extruded profile before hot rolling does not result in recrystallization, and therefore the grain size of material in all of the elements is nearly the same.

The mechanical properties of each element of the age-hardened profile were obtained by means of tensile and hardness tests to ensure that each section met the required criteria according to the standard DIN EN 485-2. The results of this investigation can be seen in Table 2 below.

Table 2: Mechanical Properties of Hot-Rolled Material in T6 Condition

\begin{tabular}{|c|c|c|c|c|}
\hline & YS [MPa] & UTS [MPa] & $\mathrm{E}_{\text {lt }}[\%]$ & HBW2.5/62.5 \\
\hline Element 1 & $313 \pm 0$ & $330 \pm 1$ & $11,1 \pm 0,5$ & $99 \pm 1$ \\
\hline Element 2 & $342 \pm 5$ & $351 \pm 4$ & $8,5 \pm 0,6$ & $104 \pm 0$ \\
\hline Element 3 & $319 \pm 3$ & $335 \pm 3$ & $9,1 \pm 1,2$ & $98 \pm 3$ \\
\hline DIN EN 485-2 & $\geq 260$ & $\geq 310$ & $\geq 7$ & $\geq 94$ \\
\hline
\end{tabular}

Independent of the element of the hot-rolled profile, all of the tested specimens meet the necessary criteria for YS, for UTS, for $\mathrm{E}_{\mathrm{lt}}$, and for hardness. Thus, the proposed production chain consisting of solution annealing, intermediate hot rolling, water quenching from the rolling temperature, and subsequent aging allows manufacturers to achieve the mechanical properties of the material 
conforming to the T6 condition. It is worth mentioning that element 2 exhibits the highest strength properties (YS, UTS and hardness) and the lowest elongation at fracture, which indicate more pronounced work hardening of this element in comparison with the others. The reason for this work hardening can be explained by more severe cooling of the thinnest element during the deformation step, due to the contact with cold rolls - the end rolling temperature for element 2 reached only $141^{\circ} \mathrm{C}$, whereas for elements 1 and 3 it was $280^{\circ} \mathrm{C}$ and $236^{\circ} \mathrm{C}$ respectively.

\section{Summary}

Thickness variation in semi-finished products in two directions, i.e. longitudinal and transverse, presents a weight-saving potential for the production of safety-relevant parts of the body in white, such as b-pillars. The production of such semi-finished products can be achieved due to a combination of two metal-forming processes: extrusion and flexible rolling. Firstly, the shape with desired thickness variation in transverse direction is extruded, and then this shape is flexibly rolled in order to obtain a final thickness variation in longitudinal direction.

As a first step towards the implementation of this combined process, the hot rolling of extruded shapes with constant rolling reduction has been investigated and successfully simulated using the software QForm VX. The rolling of extruded shapes without defects is not possible when using two non-profiled cylindrical rolls. The developed simulation model allowed the design of the necessary shape of one of the working rolls, which in combination with the second cylindrical roll enabled the rolling of extruded shapes with a constant rolling reduction, without the formation of defects.

The integrated thermo-mechanical processing, i.e. hot rolling at solution annealing temperature, water quenching, natural and artificial aging, allows the achievement of the required mechanical properties in all elements of the material; these properties correspond to the T6 condition.

Further investigations will be focused on the practical implementation of a flexible rolling process in order to obtain the semi-finished products that are required to produce modified light-weight Bpillars.

\section{References}

[1] D. Lesniak, W. Libura, Extrusion of sections with varying thickness through pocket dies, Journal of Materials Processing Technology 194 (2007) 38-45

[2] O. Engler, C. Schäfer, H. Brinkman, J. Brecht, P. Beiter, K. Nijhof, Flexible rolling of aluminium alloy sheet - Process optimization and control of materials properties, Journal of Materials Processing Technology 229 (2016) 139-148

[3] G. Hirt, D. H. Dávalos-Julca, Tailored Profiles Made of Tailor Rolled Strips by Roll Forming Part 1 of 2, Steel Research International 83 (2012) 100-105

[4] QForm - Software for simulation and optimization of metal forming processes and metal profile extrusion, QFX Simulations Ltd., http://www.qform3d.com/

[5] A. Hensel, T. Spittel, Kraft - und Arbeitsbedarf bildsamer Formgebungsverfahren, Deutscher Verlag für Grundstoffindustrie, Leipzig, 1978 (in German)

[6] A.N. Levanov, V.L. Kolmogorov, S.P. Burkin, B.R. Kartak, Yu.V. Ashpur, Yu.I. Spasskiy, Contact friction in metal forming processes, Mashinostroenie, Moscow, 1975 (in Russian)

[7] B.K. Chen, P.F. Thomson, S.K. Choi, Temperature distribution in the roll-gap during hot flat rolling, Journal of Materials Processing Technology 30 (1992) 115-130

[8] M. G. Cockcroft, D. J. Latham, Ductility and the workability of metals, Journal of the Institute of Metals, 96 (1968) 33-39.

[9] O. Grydin, A. Andreiev, N. Sotirov, M. Stolbchenko, T. M. Behr, A. Ashkelianets, I. Frolov, M. Schaper, Water quenching of hot rolled aluminum strips: Process integrated heat treatment of the alloy EN AW-6082, The Journal of the Minerals Metals \& Materials Society (2018) 1-12 